\title{
Automatic and Online Pollen Monitoring
}

\author{
Jose Oteros $^{\mathrm{a}}$ Gudrun Pusch ${ }^{\mathrm{a}}$ Ingrid Weichenmeier ${ }^{\mathrm{a}} \quad$ Ulrich Heimann $^{\mathrm{d}}$ \\ Rouven Möller $^{d}$ Stefani Röseler ${ }^{c}$ Claudia Traidl-Hoffmann ${ }^{b, e, f}$ \\ Carsten Schmidt-Weber ${ }^{a}$ Jeroen T.M. Buters ${ }^{a, f}$ \\ a ZAUM, Center of Allergy \& Environment, Helmholtz Zentrum München, ${ }^{b}$ UNIKA-T, Klinikum rechts der Isar, \\ Technische Universität München, Munich, 'Department of Dermatology, Universitätsklinikum Aachen, Aachen, \\ ${ }^{d}$ Helmut Hund $\mathrm{GmbH}$, Wetzlar, and 'Outpatient Clinic for Environmental Medicine, Klinikum Augsburg, Augsburg, \\ Germany; ${ }^{\mathrm{f} C K-C A R E}$, Christine Kühne Center for Allergy Research and Education, Davos, Switzerland
}

\section{Key Words}

Aerobiology $\cdot$ Air quality $\cdot$ Automation $\cdot$ Environmental monitoring · Pollen

\begin{abstract}
Background: Pollen are monitored in Europe by a network of about 400 pollen traps, all operated manually. To date, automated pollen monitoring has only been feasible in areas with limited variability in pollen species. There is a need for rapid reporting of airborne pollen as well as for alleviating the workload of manual operation. We report our experience with a fully automated, image recognition-based pollen monitoring system, BAA500. Methods: The BAA500 sampled ambient air intermittently with a 3-stage virtual impactor at $60 \mathrm{~m}^{3} / \mathrm{h}$ in Munich, Germany. Pollen is deposited on a sticky surface that was regularly moved to a microscope equipped with a CCD camera. Images of the pollen were constructed and compared with a library of known samples. A Hirst-type pollen trap was operated simultaneously. Results: Over 480,000 particles sampled with the BAA500 were both manually and automatically identified, of which about 46,000 were pollen. Of the automatically reported pollen, $93.3 \%$ were correctly recognized. However, compared with manual
\end{abstract}

identification, $27.8 \%$ of the captured pollen were missing in the automatic report, with most reported as unknown pollen. Salix pollen grains were not identified satisfactorily. The daily pollen concentrations reported by a Hirst-type pollen trap and the BAA500 were highly correlated $(r=0.98)$. Conclusions: The BAA500 is a functional automated pollen counter. Its software can be upgraded, and so we expected its performance to improve upon training. Automated pollen counting has great potential for workload reduction and rapid online pollen reporting.

(c) 2015 S. Karger AG, Basel

\section{Introduction}

Aerobiology studies microorganisms and biological particulate matter passively transported through the air [1]. Aerobiology has multiple types of applications, such as allergy prevention $[2,3]$; crop forecasting and pest control in agronomy $[4,5]$; climate change impacts $[6,7]$; gene flow by airborne pollen [8], and cultural heritage conservation [9].

Developing new technologies for atmospheric sampling has been one of the main focuses of aerobiological

\section{KARGER 125}

(c) 2015 S. Karger AG, Basel

$1018-2438 / 15 / 1673-0158 \$ 39.50 / 0$

E-Mail karger@karger.com

www.karger.com/iaa
Correspondence to: Dr. Jeroen T.M. Buters

ZAUM, Center of Allergy and Environment

Technische Universität München

Biedersteiner Strasse 29, DE-80802 Munich (Germany)

E-Mail buters@tum.de 
research. In case of airborne pollen, the Hirst-type volumetric spore trap [10] is the most widely used sampler in the world [11] and is recommended by the European Aeroallergen Network and European Aeroallergen Society [12]. The Hirst-type volumetric trap determines pollen concentrations continuously, whereas other samplers like the Durham, Cour or Rotorod are either not volumetric or not continuous [13-16].

Airborne pollen are monitored in Europe by a network of about 400 Hirst-type pollen traps [17]. However, there is a need for more rapid, preferably instantaneous, online reporting of airborne pollen concentrations in addition to alleviating the workload of manual operation.

Automated pollen monitoring in real time could be a solution. Some alternatives to manual quantification have been developed. Most methods are based on image recognition [18-22], whereas others used biomolecular analysis, i.e. DNA [23] or chemical identification [24]. The performance of these methods is high, but they lack the ability to quickly report the information because all of them need previous manual treatment of samples.

Only a limited number of automatic systems are capable of providing pollen information in real time; these are mostly based on an air flow cytometer. To date, satisfactory real-time information has not been reported, except in areas with limited variability in pollen species [25, $26]$. For the reported methods, different pollen grains were too similar in shape and individual species were not correctly identified $[27,28]$.

Here, we report the results of a fully automated pollen monitoring system that is able to recognize at least 11 pollen taxa: the BAA500. This system uses an image recognition algorithm on batch-collected pollen. The system automatically prepares slides suitable for visual identification of airborne particles. A camera coupled with image recognition software subsequently obtains data on airborne pollen in real time with an average delay of 3-6 h. Here, we report the performance of the system compared to manual identification of the same data as the gold standard, and also in comparison to Hirst-type pollen concentrations.

\section{Materials and Methods}

Airborne pollen data were collected in 2012, 2013 and 2014 in Munich, Germany. Two samplers, the BAA500 and Hirst [10], were located within $5 \mathrm{~m}$ of each other, about $2 \mathrm{~m}$ above ground level. The sampling location was $510 \mathrm{~m}$ a.s.l., with an annual mean temperature of $10^{\circ} \mathrm{C}$ and an accumulated annual rainfall of $950 \mathrm{~mm}$ [29].

Automatic Pollen Monitoring
Automated Pollen Monitoring

The BAA500 samples at $60 \mathrm{~m}^{3} / \mathrm{h}$ of which the central flow, i.e. $6 \mathrm{~m}^{3} / \mathrm{h}$, is used in the virtual cascade impactor. A virtual impactor is a device that separates particles by size into two air streams [30]. The virtual impactor is housed in an air-conditioned compartment. The fraction containing the pollen was impacted onto a sticky surface made from gelatine and glycerine (fig. 1). The impactor is run intermittently, in our case $1 \mathrm{~min}$ on, $5 \mathrm{~min}$ off, freely adjustable. Samples are collected during 3 hourly periods $\left(3 \mathrm{~m}^{3}\right.$ during each sampling period), $24 \mathrm{~m}^{3}$ of air every day. Additional technical information about the device can be obtained from the official website www.hund.de/en/instruments/pollen-monitor. After one sampling period, the sample was moved by a robotic rotating disk to the next station that heated the sample to $90^{\circ} \mathrm{C}$. The sticky surface was thus melted in order to align all pollen grains to facilitate the focusing of the CCD camera at the next station. The sample is analyzed at 120 random positions (sub-samples), covering $30 \%$ of the sampled surface. Then 210 images with different optical focuses were taken per sub-sample. The information of all the images was then stacked into one image that was analyzed and stored. This image was then compared to a library of known images.

Fifty-eight criteria (e.g. length, broadness, diameter, number of apertures and external texture) were used for automatic classification. Results of each identified particle, including its image, were stored enabling visual inspection and manual corrections. This part of the analysis is only visible to the operator of the BAA500 and was used to compare automatically generated pollen identification with manual identification (called labeling, i.e. the correct naming of each pollen grain). The automatic identification was reported online (http://www.hund.de/de/instrumente/ pollenmonitore/pollenfluginformation.html). The BAA500 reported data on airborne pollen concentrations every $3 \mathrm{~h}$ (8 reports per day; the time interval is adjustable).

The manual identification by an expert aerobiologist was considered the gold standard, i.e. true counts. The automatic identifications were classified as true positives, false positives and false negatives. A dataset of airborne pollen concentrations made by automatic identification and another dataset of airborne pollen concentrations made by human identification were generated.

\section{Conventional Pollen Monitoring}

Hirst-type volumetric traps [10] were operated following the minimum recommendations of the European Aeroallergen Society [12]. The Hirst-type trap sampled at a continuous volume of $10 \mathrm{l} / \mathrm{min}$ ( $14.4 \mathrm{~m}^{3}$ of air every day). Slides were analyzed by counting pollen along 4 horizontal transects with a width of $0.249 \mathrm{~mm}$, in 12-hour intervals, according to a standardized method of the German Pollen Information Service Foundation (PID) [31]. Hirst data were expressed as daily concentrations (grains $/ \mathrm{m}^{3}$ ).

Analysis

To test the performance of the BAA500, three levels were defined:

1 BAA500 Reliability. Availability of online data using the automatic system was calculated as the percentage of time that the instrument reported data during three consecutive pollen seasons (2012-2014).

2 BAA500 Classification Performance. The consistency of the BAA500 within itself, i.e. comparing the manual identification (gold standard/true counts) with the counts generated by image

Int Arch Allergy Immunol 2015;167:158-166 


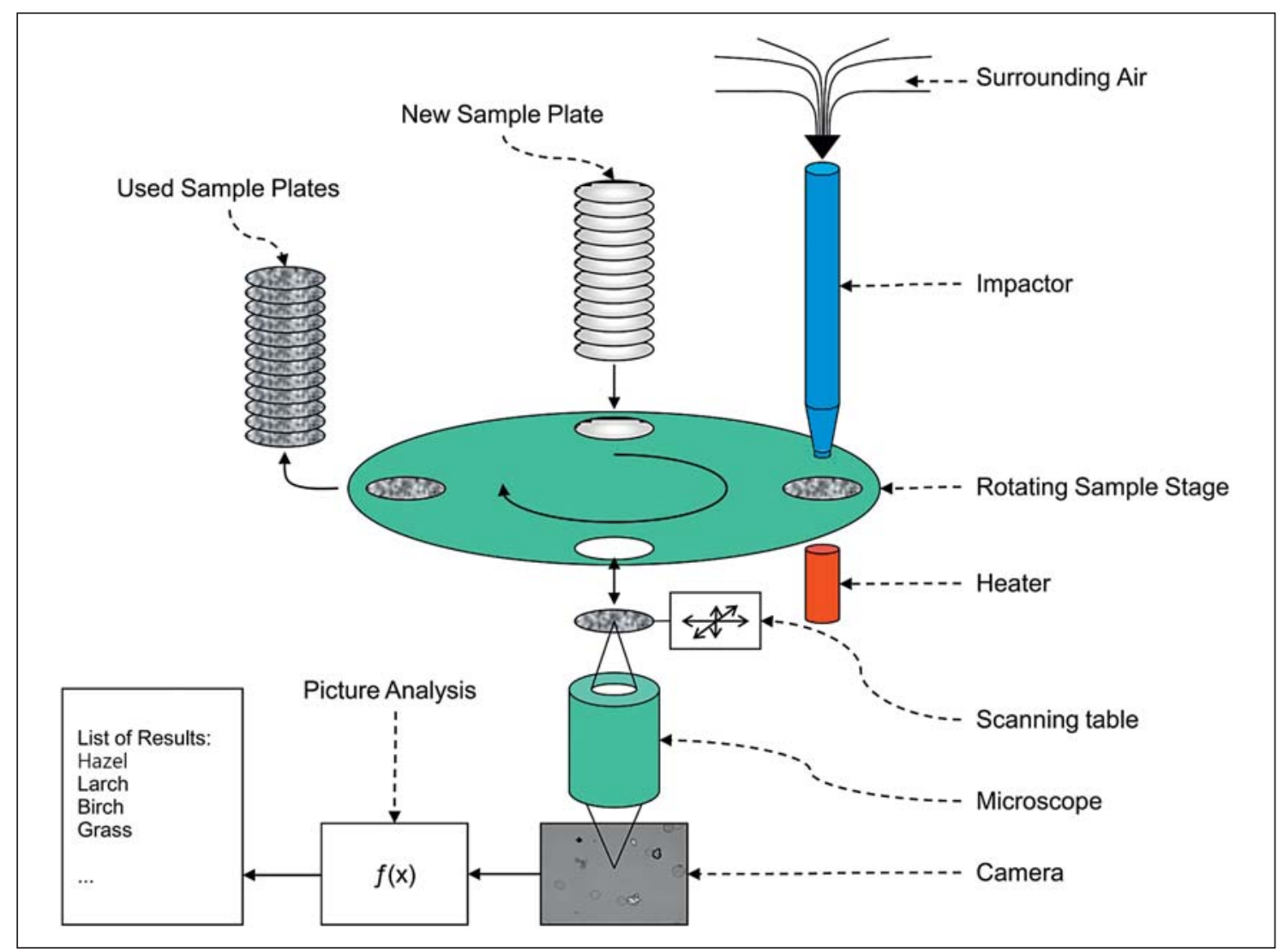

Fig. 1. Principle of operation of the BAA500. Particles from air including pollen are sampled with a virtual impactor on a slide with a 'sticky' surface that is moved with a robotic rotating table to a high-resolution camera. Scanned images are analyzed for pollen by intelligent analyzing software.

recognition (automatic count), was tested during 2012. Individual counts produced by the BAA500 were manually classified as true positives (TP), false positives (FP), true negatives (TN) and false negatives (FN), following the standard methods used to measure performance in binary classification tests [32]. The performance of the system identifying each pollen grain was measured by the percentage of different quality parameters and by the calculation of two other statistical summary parameters: sensitivity, given by formula (1), and positive predictive value (PPV), given by formula (2). Sensitivity refers to the proportion of actual pollen grains that are correctly identified as such (e.g. of the 5,908 birch pollen that the BAA500 should have recognized, 4,724 true identifications were reported) and positive predictive value refers to the proportion of BAA500 identifications that are true (e.g. of the 5,137 automatic identifications as birch, 4,724 were indeed birch pollen grains).

$$
\begin{aligned}
& \text { Sensitivity }=\frac{T P}{T P+F N} \\
& P P V=\frac{T P}{T P+F P}
\end{aligned}
$$

3 Comparison of BAA500 versus Hirst-Type Concentrations during 2012. For the BAA500, both automatic identifications and data produced following manual correction (to compare instrument capture efficacy) were used. Pearson's correlations for total and specific pollen types were calculated.

\section{Results}

\section{BAA500 Reliability}

One BAA500 has been running in Munich, Germany, since 2012. Initially, the system showed a malfunction by skipping single samples, resulting in a high percentage of time without monitoring. Reliability is shown in figure 2. The time of monitoring online was $64 \%$ in 2012 . This increased to 88 and $82 \%$ in 2013 and 2014, respectively. Sampling was sometimes interrupted by a single $>7$-day failure of the device. If we exclude these events (i.e. in 2013), then one or more 3-hour samples was missing in $16 \%$ of the time, which resulted in an average reported 


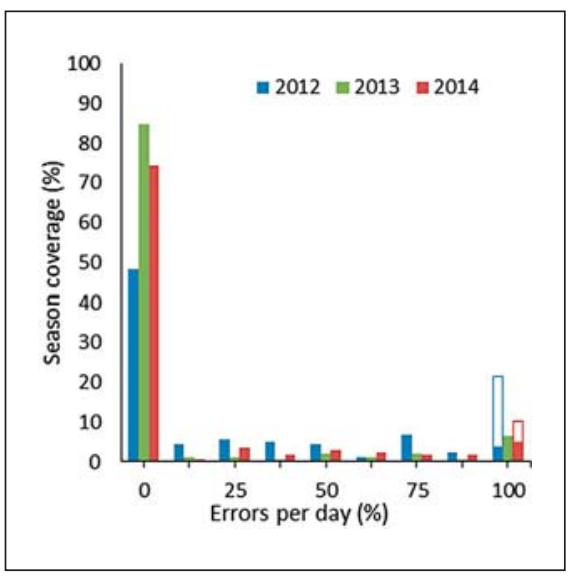

Fig. 2. BAA500 reliability during the pollen season 2012-2014. In 2013 , for instance, all data points were available for $85 \%$ of the days (max. eight 3-hour data points, $100 \%$ availability). In 2013 , for $8 \%$ of the days all data points were missing ( $0 \%$ availability). Open bars show missing data due to a single failure ( $>7$ days; instrument breakdown).

pollen count that was based on less than 8 daily samples ( $84 \%$ of days fully covered). Complete days were missing in $6 \%$ of the cases. The percentage of days with complete coverage increased during the study period. Concomitantly, the percentage of whole days and days with some samples missing was reduced. Most of the time in which the system was not monitoring in 2014 was due to one event ( $>7$-day failure). These errors might be reduced with technological improvement.

\section{BAA500 Classification Performance}

In order to test the performance of the BAA500, we analyzed its success rate in pollen identification. During the experiment, the BAA500 recognized 480,000 particles of which about 46,000 were known pollen from different species. All of the pollen grains reported by the BAA500 were concomitantly labeled automatically and manually (corrected labeling; table 1). A total of $72.2 \%$ of the manually labeled pollen grains were correctly classified by the system (true positives). Of the particles recognized as known pollen, $93.3 \%$ of cases were correctly classified and only $6.7 \%$ were identified as being false positives. Salix pollen grains were not identified satisfactorily (76 of 534). Rare pollen $(<100$ pollen grains/season) probably obtained a low performance because the instrument needs reference examples in order to label pollen correctly.

Figure 3 summarizes the performance of the system at identifying each taxon of pollen, excluding rare pollen.

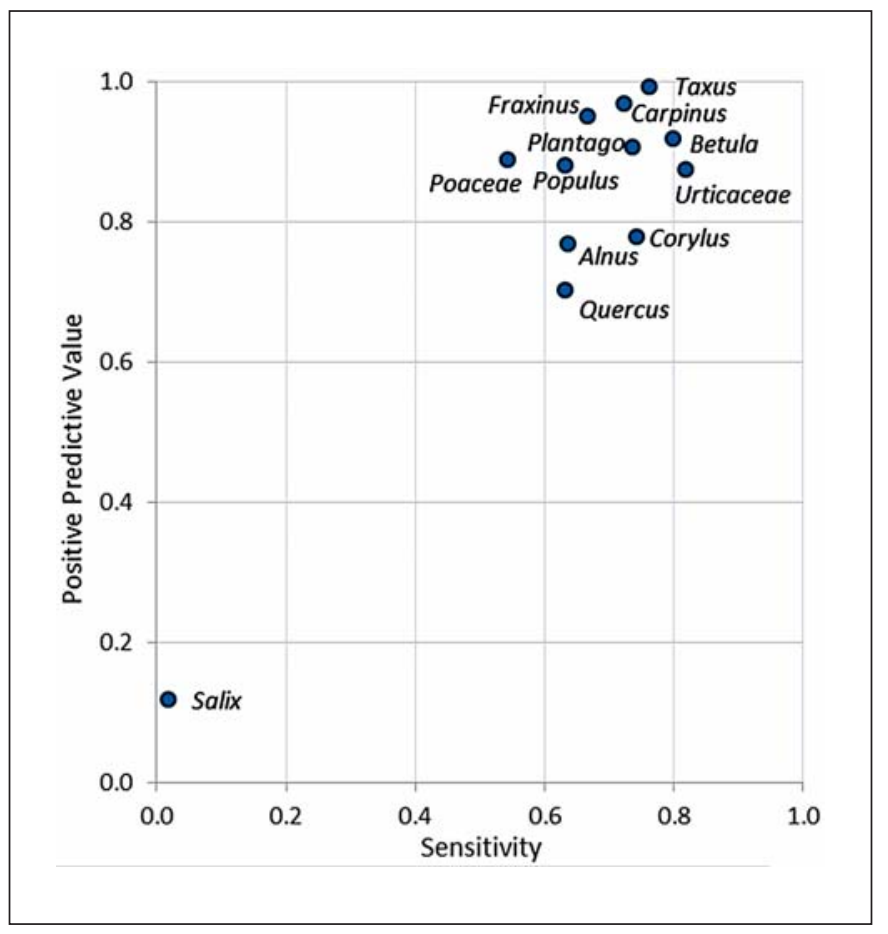

Fig. 3. BAA500 ability to recognize different pollen. Sensitivity is the proportion of manually identified particles that were automatically identified (including false-positive and false-negative results). The positive predictive value is the proportion of automatic identifications that were correct. For instance, only $80 \%$ of the available Taxus pollen were automatically identified. Of those automatically identified, $100 \%$ were correct.

The $\mathrm{x}$-axis shows the proportion of actual particles that were correctly identified, and the $y$-axis the proportion of automatic identifications that were true. As can be seen, most pollen taxa are located in the upper right corner of the graph, representing optimal system performance. Of these, the best performance was seen with Betula, which is the pollen grain nearest to the top right corner. The BAA500 reported more than $80 \%$ of manually identified Betula pollen grains correctly and when the BAA500 reported automatic identification, it was correct in more than $90 \%$ of cases. On the other hand, Salix pollen grains were not identified correctly.

Figure 4 shows the errors of the BAA500 in reporting each pollen species. The BAA500 sometimes confused pollen types. For instance, Betula pollen grains were incorrectly reported as Alnus pollen in 6\% of cases, Fraxinus pollen was sometimes reported as Populus, and Plantago pollen was wrongly reported as Rumex or Poaceae pollen. 
Fig. 4. Identification of the correctness of the BAA500: $100 \%$ is the total number of one pollen type that the BAA should have identified (determined manually). Different colors refer to the proportion of each pollen kind automatically identified as each of the different options. For instance, in the case of Betula, $80 \%$ of airborne pollen grains were automatically recognized as such. About $10 \%$ of the Betula pollen were classified by BAA500 as unknown pollen; $7 \%$ of the (manually determined) Betula pollen were wrongly classified as Alnus. Another $3 \%$ were classified as no pollen or another kind of pollen. All pollen less than $3 \%$ wrongly classified were combined into the category 'others'. The largest error was 'unknown pollen', i.e. the BAA500 could not recognize the pollen because that specific appearance was not stored in the library. This error may be reduced by storing more examples of specific pollen in the library.

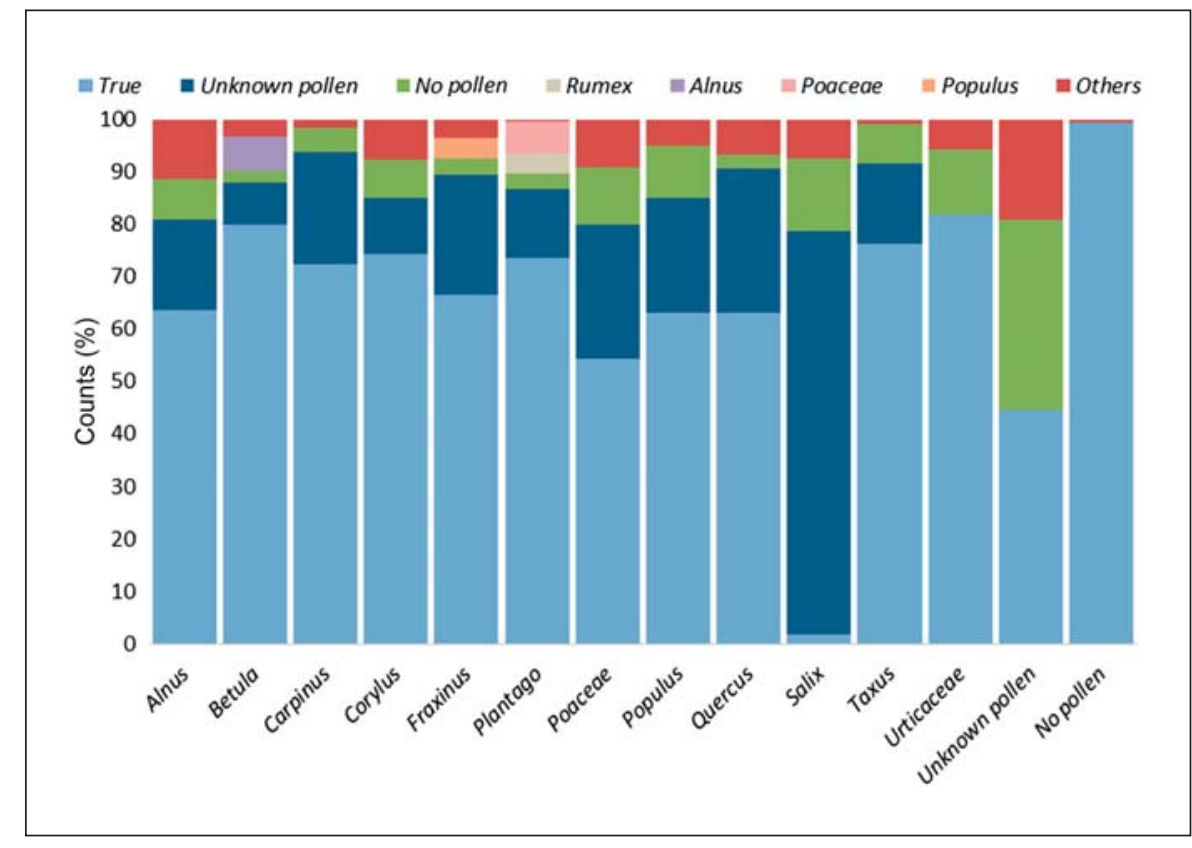

Table 1. Recognition and error rates for the different pollen species by the BAA500

\begin{tabular}{|c|c|c|c|c|c|c|c|c|c|c|}
\hline Pollen type & Manual & Automatic & Difference & $\mathrm{DF} \%$ & $\mathrm{TP}$ & TP\% & FP & $\mathrm{FP} \%$ & FN & FN\% \\
\hline Taxus & 17,732 & 13,606 & 4,126 & 76.7 & 13,519 & 99.4 & 87 & 0.6 & 4,213 & 23.8 \\
\hline Fraxinus & 5,916 & 4,141 & 1,775 & 70.0 & 3,939 & 95.1 & 202 & 4.9 & 1,977 & 33.4 \\
\hline Carpinus & 4,955 & 3,699 & 1,256 & 74.7 & 3,586 & 96.9 & 113 & 3.1 & 1,369 & 27.6 \\
\hline Populus & 2,913 & 2,087 & 826 & 71.6 & 1,839 & 88.1 & 248 & 11.9 & 1,074 & 36.9 \\
\hline Urticaceae & 2,345 & 2195 & 150 & 93.6 & 1,918 & 87.4 & 277 & 12.6 & 427 & 18.2 \\
\hline Poaceae & 1,250 & 763 & 487 & 61.0 & 678 & 88.9 & 85 & 11.1 & 572 & 45.8 \\
\hline Plantago & 1,144 & 928 & 216 & 81.1 & 841 & 90.6 & 87 & 9.4 & 303 & 26.5 \\
\hline Corylus & 1,117 & 1,066 & 51 & 95.4 & 830 & 77.9 & 236 & 22.1 & 287 & 25.7 \\
\hline Salix & 534 & 76 & 458 & 14.2 & 9 & 11.8 & 67 & 88.2 & 525 & 98.3 \\
\hline Quercus & 386 & 347 & 39 & 89.9 & 244 & 70.3 & 103 & 29.7 & 142 & 36.8 \\
\hline Platanus & 91 & 93 & -2 & 102.2 & 41 & 44.1 & 52 & 55.9 & 50 & 54.9 \\
\hline Total & 46,233 & 35,781 & 10,452 & 77.4 & 33,377 & 93.3 & 2,404 & 6.7 & 12,856 & 27.8 \\
\hline
\end{tabular}

Manual = Total counts manually labelled; automatic $=$ total counts by automatic identifications; DF\% = percentage of automatic counts with respect to manual counts; $\mathrm{TP}=$ true-positive counts; $\mathrm{TP} \%=$ percentage of true-positive counts with respect to automatic counts; FP = false-positive counts; FP\% = percentage of false-positive counts with respect to automatic counts; FN = false-negative counts; FN\% = percentage of false-negative counts with respect to manual counts. 


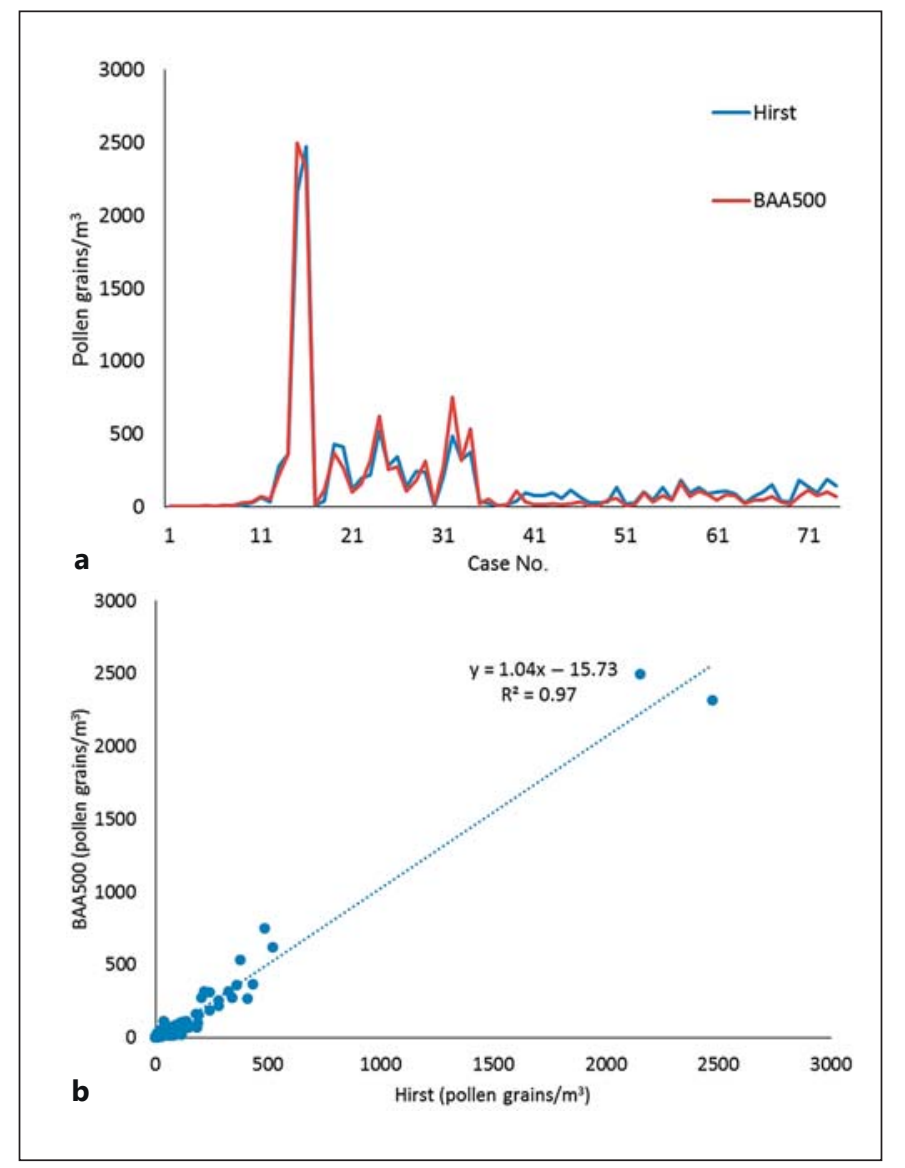

Fig. 5. Relationship between daily total pollen concentrations provided by the BAA500 (using the manually corrected dataset to be able to compare instrument capture efficacy) and a Hirst-type pollen trap. a Time line of pollen counts. b Scatterplot of BAA500 and Hirst daily concentrations. Days (cases) without data were omitted from analysis. For specific pollen types see online supplementary figure $\mathrm{S} 1$. The same curves without manual correction are given in online supplementary figure S2.

However, the largest error in all pollen species was not being able to determine which pollen it was at all (unknown pollen). Thus most of the wrong identifications were automatically classified as 'unknown' pollen rather than 'other' pollen types (fig. 4). Nearly $100 \%$ of airborne particles that were not pollen (no pollen) were not confused with pollen. The system is, therefore, able to identify pollen but reports too many of these pollen grains as unknown.

Training the instrument using local examples of pollen can reduce the fraction of unknown pollen. In Munich, using the standard reference library, $65 \%$ of the pollen grains were automatically classified as the correct pollen
Table 2. Summation of Hirst and BAA500 daily manually corrected concentrations: Pearson's r value and Wilcoxon's signed-rank test

\begin{tabular}{|c|c|c|c|c|c|c|}
\hline Pollen & Hirst & BAA500 & $\begin{array}{l}\text { Differ- } \\
\text { ence }\end{array}$ & $\%$ & $\mathrm{r}$ & $\begin{array}{l}\text { Wil- } \\
\text { coxon }\end{array}$ \\
\hline Taxus & 6,804 & 7,884 & $-1,080$ & -16 & $0.959^{* *}$ & 0.473 \\
\hline Urticaceae & 1,744 & 867 & 877 & -50 & $0.927^{* *}$ & 0.000 \\
\hline Fraxinus & 1,572 & 1,706 & -134 & -9 & $0.966^{* *}$ & 0.605 \\
\hline Poaceae & 840 & 443 & 397 & 47 & $0.910^{* *}$ & 0.034 \\
\hline Betula & 847 & 758 & 89 & 10 & $0.761^{* *}$ & 0.115 \\
\hline Populus & 671 & 1,148 & -477 & -71 & $0.994^{* *}$ & 0.010 \\
\hline Carpinus & 675 & 1,311 & -636 & -94 & $0.969^{* *}$ & 0.015 \\
\hline Alnus & 483 & 673 & -190 & -39 & $0.905^{* *}$ & 0.000 \\
\hline Plantago & 484 & 473 & 11 & 2 & $0.922^{* *}$ & 0.970 \\
\hline Corylus & 279 & 408 & -129 & -46 & $0.975^{* *}$ & 0.005 \\
\hline Salix & 247 & 204 & 43 & 17 & $0.787^{* *}$ & 0.250 \\
\hline Quercus & 65 & 54 & 11 & 17 & $0.486^{* *}$ & 0.052 \\
\hline Rumex & 33 & 13 & 20 & 61 & $0.436^{* *}$ & 0.179 \\
\hline Secale & 13 & 9 & 4 & 30 & $0.945^{* *}$ & 1.000 \\
\hline Artemisia & 11 & 6 & 5 & 42 & $0.545^{* *}$ & 0.763 \\
\hline Platanus & 9 & 4 & 5 & 52 & $0.243^{*}$ & 0.408 \\
\hline Fagus & 1 & 10 & -9 & -908 & -0.025 & 0.071 \\
\hline Total & 14,778 & 15,973 & $-1,195$ & -8 & $0.984^{* *}$ & 0.263 \\
\hline
\end{tabular}

species (manual counts: 100\%). After local training, automatic recognition increased to $72 \%$. False positives were reduced by training from 13 to $7 \%$. False negatives were reduced from 35 to $28 \%$.

\section{BAA500 and Hirst Comparison}

We compared airborne pollen concentrations obtained by the BAA500 with data collected by a Hirst-type pollen trap. Manually corrected data were used to compare instrument capture efficacy. Total daily pollen concentrations captured by the Hirst and BAA500 samplers, when available, showed a significant positive correlation coefficient of 0.98 ( $\mathrm{p}<0.01$; fig. 5).

All pollen types correlated significantly in daily concentrations, excluding Fagus (only 1 pollen grain $/ \mathrm{m}^{3}$; table 2). These results indicate that both air samplers have the same ability to capture particles (see the overall Pearson correlation, $r=0.98$ ). In Munich in 2012, there were eleven pollen taxa with a pollen index above 100 in both traps (the pollen index is the summation of daily pollen concentrations). Of these, the Hirst trap monitored, on average, a total of 202 pollen grains $/ \mathrm{m}^{3}$ per day during the study period, in contrast to 219 grains $/ \mathrm{m}^{3}$ by the BAA500 
(table 2). Although there were no significant differences in the total quantity of pollen trapped by both samplers, some specific pollen types were collected differently by each trap, as shown by the Wilcoxon rank test. Statistically significant differences in capture capacity were detected for Poaceae and Urticaceae (more trapped by Hirst), and Carpinus and Populus (more trapped by BAA500; see online suppl. fig. S1, S2: for all online suppl. material, see www.karger.com/doi/10.1159/000436968) between daily concentrations collected by the Hirst and automatically classified by the BAA500.

\section{Discussion}

Automated online pollen monitoring of complex pollen mixtures is currently not available, except for the BAA500. Here, we report the performance of the BAA500. The system uses a high-volume virtual impactor; pollen are deposited on a sticky surface of which digitalized images are made. An image recognition algorithm is used to compare the image to a library of known pollen. We tested the performance of the BAA500 at three levels: (1) the reliability of the instrument, (2) the performance of the image recognition software against manually determined pollen counts of the same images and (3) the performance in capture efficacy against the commonly used Hirst trap methodology.

Regarding the reliability of the instrument, in 2013, the instrument was online about $90 \%$ of the time, excluding breakdowns. The reliability of the BAA500 increased with time. The Hirst volumetric spore trap showed a reliability of nearly $100 \%$ of the time monitored. However, the workload necessary to perform effective monitoring using the Hirst-type method is high, forcing many monitoring stations to work only during the main flowering season (https://ean.polleninfo.eu/).

Regarding the performance of the BAA500, except for Salix, most of the pollen species were recognized in $>70 \%$ cases. The BAA500 seldom reported pollen wrongly (i.e. few false positives). However, the main mistake was the inability of the BAA500 to recognize some pollen, i.e. manually identified pollen was reported by the BAA500 as unknown. This error can be reduced by improving the recognition algorithm or by improving the software with more examples of pollen, as every location has pollen with morphological characteristics unknown to the standard library. The software could be modified in the future by adding the possibility of using more than one image to improve the success rate in identification. The airborne pollen levels recorded by the Hirst-type trap were similar to those reported by the BAA500. Although airborne pollen is not necessarily representative of exposure to aeroallergens $[24,33,34]$, the knowledge about the level of airborne pollen is a useful tool for managing pollinosis. In this sense, the advantage of automated pollen detection is the online reporting of airborne pollen concentrations 2-10 days before the classical method. Besides this, Hirsttype pollen traps also have errors of about $25 \%[24,34]$. To date, it is unknown which pollen trap reports the 'true' airborne concentrations. The human error involved in identifying pollen grains by light microscopy from samples collected by the Hirst-type sampler depends on the concentrations of airborne particles [35-38]. In aerobiology, the most commonly accepted error threshold for humans is a $20 \%$ difference between the actual and the reported identification, or even $30 \%$, depending on averaged concentrations of airborne pollen [12, 36, 37]. In comparison, excluding Salix, the average error in identifying common pollen taxa by the BAA500 was lower than $20 \%$, and only Poaceae showed an error higher than $30 \%$.

To date, similar success rates have been obtained by different automatic identification methods also based on image analysis, most of them exceeding 80\% [39-41]. However, these automatic identification methods need the presence of digital images and have not been fully automated to date. The BAA500 is the first system with automation of all the processes before image recognition. Other systems for automated pollen monitoring are based on an airflow cytometer, which was implemented in Japan, where most pollinosis is caused by only one species, i.e. Japanese cedar (Cryptomeria japonica) [25], but it was not successfully implanted in other areas with more biodiversity in airborne pollen [27]. For another new system (the PLAIR system) for automated aerobiological monitoring results have not been published to date [B. Clot, pers. commun.].

Highly significant correlations were obtained for atmospheric concentrations of all pollen types collected by the BAA500 and Hirst samplers, and the total quantity of pollen grains trapped by both samplers was about the same. This indicates a similar capacity to capture particles. Although all pollen types showed a significant correlation (most of them collected in the same quantity), some of them were trapped in different quantities. Three of them had differences higher than 50\% (Urticaceae, Populus and Carpinus), which may have different reasons, for example human error in pollen recognition due to differences in the quality of images sampled by the Hirst and BAA500 systems. The use of different adhesives 
may be another source of variation. Other possible reasons of variability are that the virtual impactor and Hirst collector may have differences in their ability to collect particles depending on their aerodynamic features. The BAA500 is not constantly adjusted towards wind direction as it samples at high volume from all sides, whereas Hirst-type traps are low-volume samplers, and the orifice is always pointed in the direction of prevailing winds using a wind vane, which means that sampling efficiency can be influenced by wind speed [42]. As a result, there are some inherent differences in the data collected by the BAA500 and Hirst samplers, which should be kept in mind when comparing results. It is extremely unlikely, however, that these differences would have an effect on the phenological information produced by the two samplers, e.g. the main characteristics of the airborne pollen seasons such as start dates, end dates, duration and magnitude would be the same in most cases. Some differences were expected because several authors have reported similar variations between Hirst-type traps, even when placed together and at the same height (a difference from 20 to $40 \%$ in concentrations of specific pollen types) [ 24 , $43,44]$.

Automatic identification systems are currently becoming a serious option for routine monitoring. One advantage that we did not test is that all automatic identification systems use the same counting method (i.e. have a constant error), whereas Hirst-type traps show a laboratory-to-laboratory uncertainty, which is also due to human variability [12, 35-38]. In addition, errors of about $25 \%$ between Hirst-type pollen traps are common due to instrumental and methodological variability [24, 44]. Furthermore, due to the lack of an airborne gold standard (calibrated airborne pollen concentrations), it is currently not possible to determine which instrument reports the true values.

Automatic pollen monitoring has the advantage of reproducible, online measurements, thereby greatly reducing human workload. In our opinion, the errors encountered with the BAA500 are partly inherent to aerobiology, can partly be reduced by local training and are comparable to classic methods. This should also be offset against the advantages of automation: stable methodology, constant error, reduced workload and rapid online data analysis. Although there is room for improvement, automatic pollen monitoring has advantages over the classical methodology in monitoring airborne pollen concentrations.

\section{Acknowledgments}

The excellent assistance of Christine Weil in pollen counting and Danijel Kupresanin for taking care of the BAA500 are greatly appreciated.

\section{Disclosure Statement}

U. Heimann and R. Möller are employees of Hund $\mathrm{GmbH}$, the manufacturer of the BAA500, and assisted in installing the instrument and in automated data processing. Financial support was not provided by the manufacturer, except as consumables for the BAA500. All other authors report no conflict of interest.

\section{References}

1 Mandrioli P, Ariatti A: Aerobiology: future course of action. Aerobiologia 2001;17:1-10.

$\checkmark 2$ Barber D, de la Torre F, Feo F, Florido F, Guardia P, Moreno C, Quiralte J, Lombardero M, Villalba M, Salcedo G, Rodriguez R: Understanding patient sensitization profiles in complex pollen areas: a molecular epidemiological study. Allergy 2008;63:1550-1558.

3 Pauling A, Gehrig R, Clot B: Toward optimized temperature sum parameterizations for forecasting the start of the pollen season. Aerobiologia 2014;30:45-57.

4 García-Mozo H: The use of aerobiological data on agronomical studies. Ann Agric Environ Med 2011;18:1-6.

5 Oteros J, Orlandi F, Garcia-Mozo H, Aguilera F, Ben Dhiab A, Bonofiglio T, Abichou M, Ruiz-Valenzuela L, Trigo MM, Díaz de la
Guardia C, Dominguez-Vilches E, Msallem M, Fornaciari M, Galan C: Better prediction of Mediterranean olive production using pollen-based models. Agron Sustain Dev 2014; 34:685-694.

- 6 Bonofiglio T, Orlandi F, Sgromo C, Romano B, Fornaciari M: Evidences of olive pollination date variations in relation to spring temperature trends. Aerobiologia 2009;25:227237.

7 Smith M, Jager S, Berger U, Sikoparija B, Hallsdottir M, Sauliene I, Bergmann KC, Pashley $\mathrm{CH}$, de Weger L, MajkowskaWojciechowska B, Rybnicek O, Thibaudon M, Gehrig R, Bonini M, Yankova R, Damialis A, Vokou D, Gutierrez Bustillo AM, Hoffmann-Sommergruber K, van Ree R: Geographic and temporal variations in pollen ex- posure across Europe. Allergy 2014;69:913923.

8 Kwon Y, Kim D, Yim KO: Herbicide-resistant genetically modified crop: assessment and management of gene flow. Weed Biol Manag 2001;1:96-107.

-9 Ruga L, Bonofiglio T, Orlandi F, Romano B, Fornaciari M: Analysis of the potential fungal biodeteriogen effects in the 'doctorate library' of the University of Perugia, Italy. Grana 2008;47:60-69.

10 Hirst JM: An automatic volumetric spore trap. Ann App Biol 1952;39:257-265.

11 Buters J: Pollen allergens and geographical factors; in Akdis C, Agache I (eds): Global Atlas of Allergy. Zurich, European Academy of Allergy and Clinical Inmunology, 2014, vol 1, pp 36-37. 
$>12$ Galán C, Smith M, Thibaudon M, Frenguelli G, Oteros J, Gehrig R, Berger U, Clot B, Brandao R: Pollen monitoring: minimum requirements and reproducibility of analysis. Aerobiologia 2014;30:385-395.

13 Belmonte J, Canela M, Guàrdia R-A: Comparison between categorical pollen data obtained by Hirst and Cour sampling methods. Aerobiologia 2000;16:177-185.

14 Frenz DA: The effect of windspeed on pollen and spore counts collected with the Rotorod sampler and Burkard spore trap. Ann Allergy Asthma Immunol 2000;85:392-394.

-15 Okamoto Y, Horiguchi S, Yamamoto H, Yonekura S, Hanazawa T: Present situation of cedar pollinosis in Japan and its immune responses. Allergol Int 2009;58:155-162.

16 Orlandi F, Oteros J, Aguilera F, Ben Dhiab A, Msallem M, Fornaciari M: Design of a downscaling method to estimate continuous data from discrete pollen monitoring in Tunisia. Environ Sci Process Impacts 2014;16:17161725.

$\checkmark 17$ Berger U, Karatzas K, Jaeger S, Voukantsis D, Sofiev M, Brandt O, Zuberbier T, Bergmann KC: Personalized pollen-related symptomforecast information services for allergic rhinitis patients in Europe. Allergy 2013;68:963965.

18 Vezey EL, Skvarla JJ: Computerized feature analysis of exine sculpture patterns. Rev Palaeobot Palyno 1990;64:187-196.

19 Boucher A, Hidalgo PJ, Thonnat M, Belmonte J, Galan C, Bonton P, Tomczak R: Development of a semi-automatic system for pollen recognition. Aerobiologia 2002;18:195-201.

20 Holt K, Allen G, Hodgson R, Marsland S, Flenley J: Progress towards an automated trainable pollen location and classifier system for use in the palynology laboratory. Rev $\mathrm{Pa}$ laeobot Palyno 2011;167:175-183.

21 Lagerstrom R, Holt K, Arzhaeva Y, Bischof L, Haberle S, Hopf F, Lovell D: Pollen image classification using the classifynder system: algorithm comparison and a case study on New Zealand honey; in Sun C, Bednarz T, Pham TD, Vallotton P, Wang D (eds): Signal and Image Analysis for Biomedical and Life Sciences. Berlin, Springer, 2015, vol 823, pp 207-226.

22 Marcos JV, Nava R, Cristobal G, Redondo R, Escalante-Ramirez B, Bueno G, Deniz O, Gonzalez-Porto A, Pardo C, Chung F, Rodriguez T: Automated pollen identification using microscopic imaging and texture analysis. Micron 2015;68:36-46.
23 Kraaijeveld K, de Weger LA, Ventayol Garcia M, Buermans H, Frank J, Hiemstra PS, den Dunnen JT: Efficient and sensitive identification and quantification of airborne pollen using next-generation DNA sequencing. Mol Ecol Resour 2015;15:8-16.

24 Buters JTM, Thibaudon M, Smith M, Kennedy $\mathrm{R}$, Rantio-Lehtimaki A, Albertini R, Reese G, Weber B, Galan C, Brandao R, Antunes CM, Jager S, Berger U, Celenk S, Grewling L, Jackowiak B, Sauliene I, Weichenmeier I, Pusch G, Sarioglu H, Ueffing M, Behrendt H, Prank M, Sofiev M, Cecchi L, Grp HW: Release of Bet $\mathrm{v} 1$ from birch pollen from 5 European countries. Results from the HIALINE study. Atmos Environ 2012;55: 496-505.

25 Yamada T, Saito H, Fujieda S: Present state of Japanese cedar pollinosis: the national affliction. J Allergy Clin Immunol 2014;133:632639.

26 O'Connor DJ, Healy DA, Hellebust S, Buters JT, Sodeau JR: Using the WIBS-4 (waveband integrated bioaerosol sensor) technique for the on-line detection of pollen grains. Aerosol Sci Technol 2014;48:341-349.

27 Kawashima S, Clot B, Fujita T, Takahashi Y, Nakamura K: An algorithm and a device for counting airborne pollen automatically using laser optics. Atmos Environ 2007;41:79877993.

-28 O'Connor DJ, Iacopino D, Healy DA, O'Sullivan D, Sodeau JR: The intrinsic fluorescence spectra of selected pollen and fungal spores. Atmos Environ 2011;45:6451-6458.

29 DWD: Deutscher Wetterdienst. 2014, http:// www.dwd.de/.

30 Rantio-Lehtimaki A, Viander M, Koivikko A: Airborne birch pollen antigens in different particle sizes. Clin Exp Allergy 1994;24:2328.

31 Winkler H, Ostrowski R, Wilhelm M, Bergmann KC: Pollenbestimmungsbuch der Stiftung Deutscher Polleninformationsdienst. Berlin, Takt, 2001.

32 Fawcett T: An introduction to ROC analysis. Pattern Recognit Lett 2006;27:861-874.

33 Galan C, Antunes C, Brandao R, Torres C, Garcia-Mozo H, Caeiro E, Ferro R, Prank M, Sofiev M, Albertini R, Berger U, Cecchi L, Celenk S, Grewling L, Jackowiak B, Jager S, Kennedy R, Rantio-Lehtimaki A, Reese G, Sauliene I, Smith M, Thibaudon M, Weber B, Weichenmeier I, Pusch G, Buters JT: Airborne olive pollen counts are not representative of exposure to the major olive allergen Ole e 1. Allergy 2013;68:809-812.
34 Buters JTM, Prank M, Sofiev M, Pusch G, Albertini R, Annesi-Maesano I, Antunes C, Behrendt $\mathrm{H}$, Berger $\mathrm{U}$, Brandao R, Celenk S, Galan C, Grewling L, Jackowiak B, Kennedy R, Rantio-Lehtimaki A, Reese G, Sauliene I, Smith M, Thibaudon M, Weber B, Cecchi L: Variation of the group 5 grass pollen allergen content of airborne pollen in relation to geographical location and time in season. J Allergy Clin Immunol 2015;136:87-95.

35 Gottardini E, Cristofolini F, Cristofori A, Vannini A, Ferretti M: Sampling bias and sampling errors in pollen counting in aerobiological monitoring in Italy. J Environ Monitor 2009;11:751-755.

36 Sikoparija B, Pejak-Sikoparija T, Radisic P, Smith M, Soldevilla CG: The effect of changes to the method of estimating the pollen count from aerobiological samples. J Environ Monit 2011;13:384-390.

37 Oteros J, Galan C, Alcazar P, DominguezVilches E: Quality control in bio-monitoring networks, Spanish Aerobiology Network. Sci Total Environ 2013;443:559-565.

38 Comtois P, Alcazar P, Néron D: Pollen counts statistics and its relevance to precision. Aerobiologia 1999;15:19-28.

39 Dell'Anna R, Cristofori A, Gottardini E, Monti F: A critical presentation of innovative techniques for automated pollen identification in aerobiological monitoring networks; in Kaiser B (ed): Pollen: Structure, Types and Effects. New York, Nova Science, 2010, vol 1, pp 273-288.

40 Holt KA, Bennett KD: Principles and methods for automated palynology. New Phytol 2014;203:735-742.

41 Bonton P, Boucher A, Thonnat M, Tomczak R, Hidalgo PJ, Belmonte J, Galan C: Colour image in 2D and 3D microscopy for the automation of pollen rate measurement. Image Anal Stereol 2001;20:527-532.

42 Peel RG, Kennedy R, Smith M, Hertel O: Relative efficiencies of the Burkard 7-day, Rotorod and Burkard personal samplers for Poaceae and Urticaceae pollen under field conditions. Ann Agric Environ Med 2013;21:745-752.

43 Pedersen BV, Moseholm L: Precision of the daily pollen count. Identifying sources of variation using variance component models. Aerobiologia 1993;9:15-26.

44 Tormo Molina R, Maya Manzano JM, Fernandez Rodriguez S, Gonzalo Garijo Á, Silva Palacios I: Influence of environmental factors on measurements with Hirst spore traps. Grana 2013;52:59-70. 